\title{
Salinity Problem and its Management in Coastal Belt of Odisha, India
}

\author{
Ashok Kumar Das*, Kishore Chandra Senapati* and Shishira Kanta Behera** \\ Institute of Agricultural Sciences, SOA University, Odisha, India \\ *Corresponding author
}

\begin{tabular}{|l|}
\hline Ke y w o r d s \\
Salinity, Coastal \\
plain, Water \\
logging, Brakish \\
water
\end{tabular}

The coastal belt of Odisha extends over 480 kilometers from mouth of Subarnarekha river in the north to the Chilika lake in the south. The plain occupies the outfall regions of major rivers like Mahanadi, Bramhani, Baitarani, Subarnarekha and Rusikulya. It covers one of the most fertile land in the eastern parts of the country and support the major food grain production in the state. But due to the proximity of sea, cyclonic hazard and saltwater ingress through tidal channels have restricted the availability of acceptable quality of water for irrigation as well as drinking. Both saline and fresh water co-exists in the system, after inter changing their position. Water logging and salinity water which destroy the production potential of coastal irrigated lands are a major threat to food security. The major options to address these problem include (i) improved irrigation management to reduce groundwater accessions (ii) evolution and introduce of salt tolerant crops. (ii) mitigation of effects of salinity through afforestation, structural measures etc.

\section{Introduction}

The state of Odisha with a geographical area of 155,707 sq. kilometers stretches along the eastern coast of India surrounded by Bay of Bengal in the East, States of Bihar, Jharkhand and West Bengal on the North, Chhatisgarh and Madhyapradesh on the West and Andhra Pradesh in the South side. Physiographically the state is divided into four distinct zones, the coastal plains, Northern Plateu, Central table lands and Eastern Ghat regions. The coastal belt of Odisha stretches $480 \mathrm{kms}$ long and 10 to $50 \mathrm{kms}$ broad occupies the outfall regions of the major rivers. It represents most fertile land in the eastern part of the country. This plain built up by a series of deltas at the mouths of rivers Subernrekha, Bhudabalanga, Baitarani, and Mahanadi. All the major river basin terminates at the coast (Fig-1).

Three parallel belts are distinguishable: salt tract -5 to $6 \mathrm{~km}$ from the shore, followed westwards by the arable alluvial tract and submontane tract. These rivers are meandering and braided with abandoned river channels lakes, flood plains and levees. Sand dunes form a prominent feature along with 
parts of the coast. Both fresh and saline water co-exist in the system, often interchanging their position (fig-2). In the multiple aquifer system in this coastal tract a variety of situations have evolved depending upon nature of sediments, aquifer properties, freshwater head the outlet point etc.

(i) Fresh water overlying salt water.

(ii) Salt water overlying fresh water.

(iii) Fresh and salt water bodies alternating.

(iv) All through salinity.

The width of the coastal saline tract varies from $10 \mathrm{~km}$. in Balasore district to $60 \mathrm{kms}$ in Cuttack. The depth wise distribution of saline and fresh water aquifers is nonuniform. In north in Subarnarekha - Budhabalanga basins aquifers are generally fresh down to $300 \mathrm{~m}$ depth barring a narrow coastal strip. In Bramhani - Mahanadi basins large areas in Kendrapara and Jagatsinghpur districts aquifers are saline to brakish down to 60-320 $\mathrm{m}$ depth. In the eastern part of Puri district fresh water aquifers occur down a depth of 100 m. In Puri-Bramhagiri Siruli tact aquifers are saline to brakish natures at all depth. Also within the tidal reach of the rivers influence of sea water intrusion into top aquifers having hydraulic connection with the river, will be remarkable.

A sub-tropical monsoonic climate prevails in the coastal region with an annual average rainfall of the order of $1500 \mathrm{~mm}$. Paddy is the principal crop during kharif and where irrigation facilities are available the second crop i.e. Rabies coming up. About 0.4 million $\mathrm{Ha}$ area is exposed to saline inundation and 0.075 million $\mathrm{Ha}$ area water logged in deltaic region. Irrigation with saline water affects adversely crop growth and productivity of soil. High sub-soil water, acidity, seepage from canals, poor drainage, backwater flow, intrusion of sea water leads to salinity. Systematic surveys have shown that 1.5 million Ha area irrigated with poor quality of water in several states in India. In the world, 50 million Ha are affected by salinity spread over 24 countries. The quality of water in most of the rivers in Orissa except a few is good. The water of river, Mahanadi (upper end), Kharasrota, Rusikulya, Nagabali, Indrabati, are good quality and there EC is less than $0.35 \mathrm{dS} / \mathrm{m}$. The river water of Bramhani, Baitarani, Mahanadi (lower), Subarnarekha, Devi are slightly saline and EC is $0.45-1.41 \mathrm{dS} / \mathrm{m}$. (Table 1)

There are quite a number of factors contributing to the growth of salinity in soil and water in coastal Orissa. With declining and uncertain rainfall from year to year, there is less fresh water available on the to recharge the underground layers are usually affected by laterally ingress of saline water from sea. In course of time sea mouths have been unusually silted up, the saline water which enters into the rivers by tidal waves remains for a long time. As a result, there is a prolonged logging of saline water in rivers and creeks. Usually mangroves of the coastal belt absorb to a great extent of salinity. But the existence of mangroves have been gradually depleted by the people to meet their growing needs like fuel wood, timber, prawn culture and cultivation.

\section{Classification of saline water for irrigation}

Water is being a universal solvent, several salts are dissolved in it. The main soluble constituents are cautions (positive charged ions) of calcium, magnesium, sodium and potassium and anions (negative charged ions) of sulphate, chloride, bicarbonate and nitrate. Some other such as lithium, silicon, bromine, boron, arsenic, chromium, manganese, lead etc. may be present in minor quantities. Among all these soluble constituents, calcium, magnesium, sodium, chloride, sulphate and bicarbonates are prime 
importance in determining the quality of irrigation water and its suitability for irrigation. Other factors such as texture, structure of soil, its drainage, crop and climate are equally important in determining the suitability water for irrigation.

The quality irrigation water generally expressed on the basis of total salt content, relative concentration of sodium and bicarbonate content. All irrigation water is classified on the basis of total salt content, USA Salinity Laboratory classified irrigation water on EC is classified in four groups (Fig$3)$.

$\mathbf{C}_{1}$ Low salinity water - If the EC is less than $0.25 \mathrm{dS} / \mathrm{m}$ the irrigation water is classified as low salinity. It can be used for irrigation all soils and most crops.

$\mathbf{C}_{2}$ Medium salinity water - It has EC between 0.25 to $0.75 \mathrm{dS} / \mathrm{m}$. The water can be safely used for crops with moderate salt tolerance.

$\mathbf{C}_{3} \quad$ High Salinity water - Water within ranges of 0.75 to $2.25 \mathrm{dS} / \mathrm{m}$ is called high salinity water. This water can be used for salt tolerant crops by providing good drainage.

C 4 Very high Salinity - If EC is more than $2.25 \mathrm{dS} / \mathrm{m}$ the water is classified as very high salinity water not suitable for irrigation purpose.

Similarly the water is classified to $\mathrm{S}_{1}, \mathrm{~S}_{2}, \mathrm{~S}_{3}$, and $S_{4}$, depending upon the amount of sodium presence in it.

\section{Classification of irrigation water based on EC, by C.S.S. R.I}

The CSSRI suggested another classification of irrigation water based on EC, SAR and boron construction.

\section{Salinity management strategies in coastal command area}

Some of the important management practices are adopted for the alleviation of salinity in the coastal command are

\section{Irrigation system improvement}

Improved irrigation management can reduce the rate at which the salinity develops. Appropriate irrigation scheduling and use of improved low-volume application technologies can slow the salt build up.

The basic principle in low volume application technologies is the improvement in uniformity water application at reduced depth of application.

\section{Salinity mitigation strategy}

Controlling of salinity through installation of drainage system is a positive action but is capital intensive. It is faced with several problems like effluents, absence of group activity, physiological and political attitude of the farming community.

\section{Conjunctive use of fresh and saline water}

The saline water could be used after blending with fresh water or can be alternated with fresh water in a cyclic manner. Irrigation with fresh water in the beginning and saline water subsequently.

\section{Shallow water table management}

Management of shallow water table rather than always draining to a specific depth is a new research concept and can be extremely beneficial. The amount of drainage volume produced by drainage system can be reduced by the amount of water used by the crop from shallow water table. 


\section{Selection of salt tolerant crops}

It has been established that agricultural crops differ significantly in their tolerance to concentration of soluble salts in the root zone. Selection of crop is a primary tool to maximize production under saline environment. The limits of tolerance to various crops to salts and $\mathrm{p}^{\mathrm{H}}$ of soil are given in table -3 . The lower levels indicate $0-10 \%$ reduction in crop yields and upper values indicate $10-25 \%$ reduction in the crop yields command to normal soils.

\section{Afforestation}

The potential of certain mangrove forest species draw more water than agricultural crops because of their deeper root system, higher transpiration rate throughout the year and ability to minimize recharge from rain. Species like Casurina Equisetfolia, Tamarix Articulata and Prosopic Julifora could withstand both high water table and salinity. And protection of existing mangrove forest from the rehabilitation of refugees.

Table.1 Quality of water in some Odisha rivers

\begin{tabular}{|l|c|c|}
\hline River & EC ds/M & $\mathbf{P}^{\mathbf{H}}$ \\
\hline Rushikulya & 0.274 & 8.2 \\
\hline Nagabali & 0.1777 & 8.1 \\
\hline Devi & 0.647 & 8.3 \\
\hline Bhudabalanga & 0.448 & 8.4 \\
\hline Kharasrota & 0.339 & 8.3 \\
\hline Subarnrekha & 0.725 & 8.4 \\
\hline Bramhani & 1.392 & 8.3 \\
\hline Indrabati & 0.269 & 8.0 \\
\hline Baitarani & 1.64 & 8.5 \\
\hline Mahanadi (Lower) & 1.640 & 8.1 \\
\hline Mahanadi (Upper) & 0.22 & 8.2 \\
\hline
\end{tabular}

Table.2 Classification of irrigation water

\begin{tabular}{|c|c|c|c|}
\hline Class & $\mathrm{EC}(\mathrm{dS} / \mathrm{m})$ & Quality rating & Soil \& crops for which suitable \\
\hline $\mathrm{A}_{1}$ & $<1.5$ & Normal water & Most crops, most soil \\
\hline $\mathrm{A}_{2}$ & $1.5-3$ & Low salinity & $\begin{array}{l}\text { Most crops on light and medium } \\
\text { textured soil. }\end{array}$ \\
\hline$A_{3}$ & $3-5$ & Moderate salinity water & Semi tolerant crops \\
\hline $\mathrm{A}_{4}$ & $5-10$ & Saline water & $\begin{array}{l}\text { Tolerant crops, soil should have } \\
\text { excellent drainage }\end{array}$ \\
\hline $\mathrm{A}_{5}$ & $>10$ & High salinity water & $\begin{array}{l}\text { Not suitable for irrigation Under } \\
\text { ordinary condition }\end{array}$ \\
\hline
\end{tabular}


Table.3 Crop tolerance to salinity

\begin{tabular}{|l|c|c|}
\hline \multicolumn{1}{|c|}{ Crop } & EC dS/m & $\mathbf{P}^{\mathbf{H}}$ \\
\hline Barley & $10-15$ & $9-9.5$ \\
\hline Sugarbeet & $10-15$ & $9-9.5$ \\
\hline Cotton & $5-10$ & $9-9.5$ \\
\hline Wheat, sayabean & $5-10$ & $8.8-9.3$ \\
\hline Sorghum rice & $5-10$ & $8.5-9.0$ \\
\hline Mustard & $5-10$ & $8.5-9.0$ \\
\hline Sugar cane & $3-5$ & $8.5-9.0$ \\
\hline Groundnut, maize & $3-5$ & $8.5-9.0$ \\
\hline Pulses & $1.5-3$ & 8.5 \\
\hline
\end{tabular}

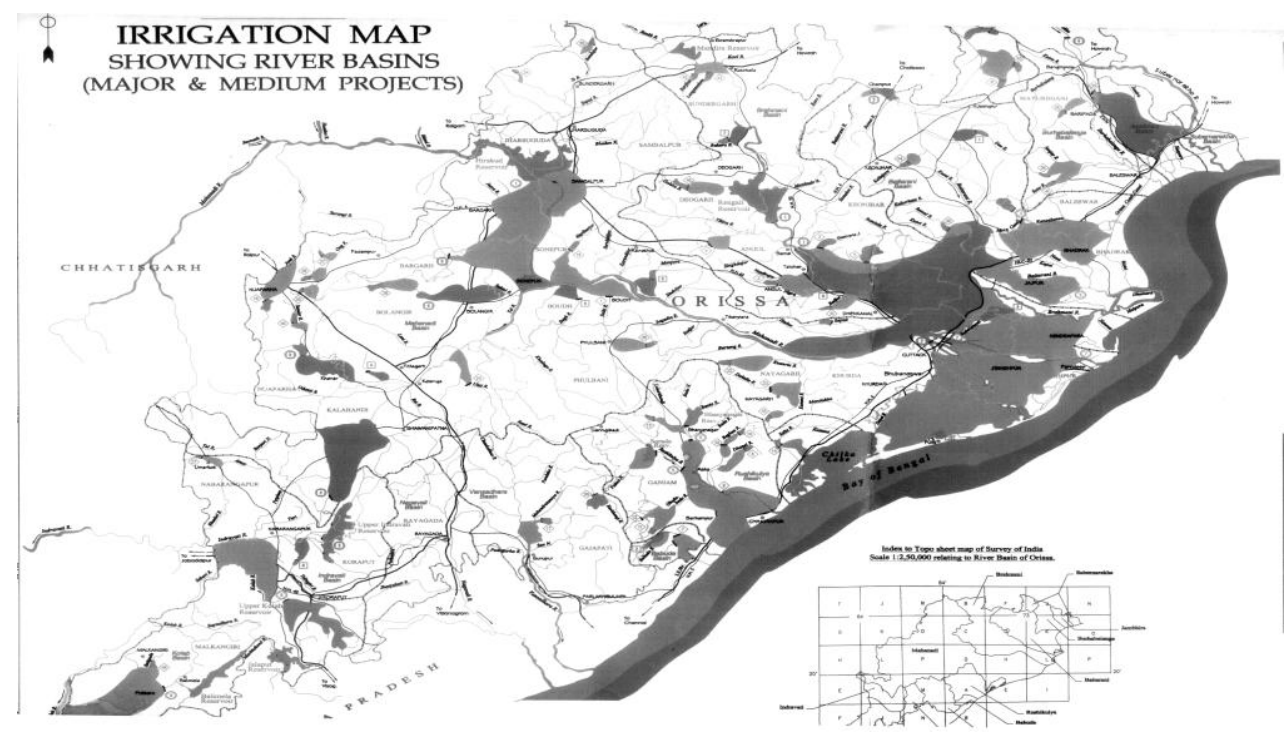

Fig.1 Showing major river basins of Odisha

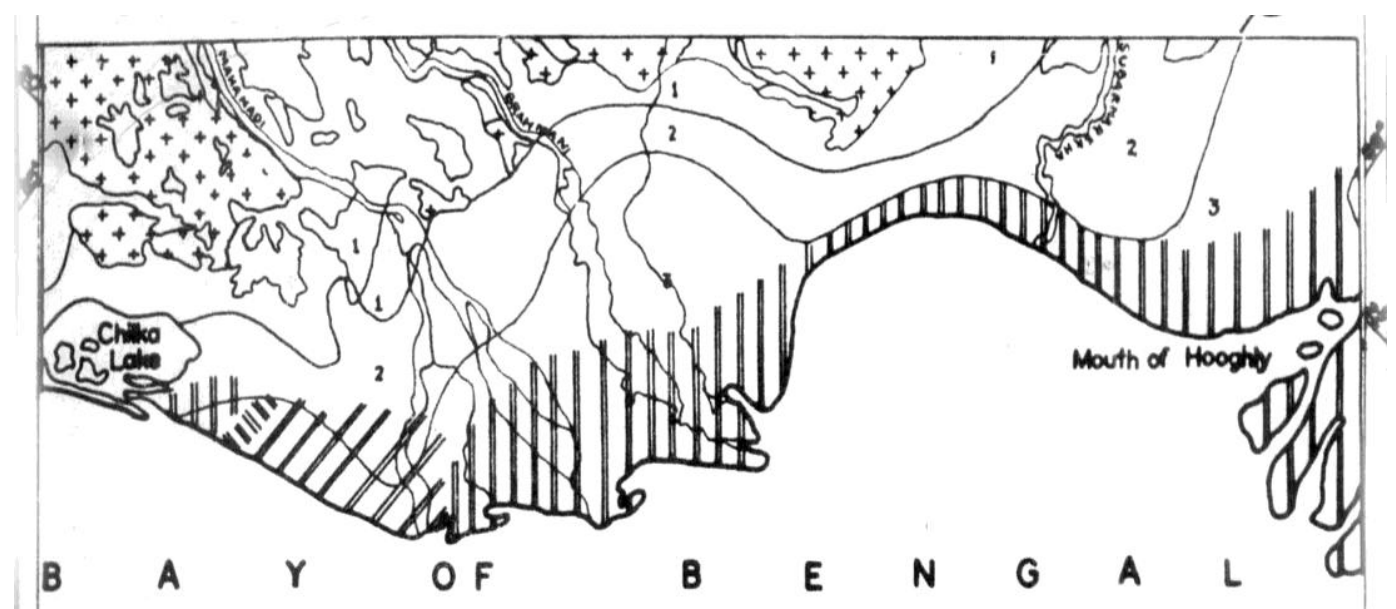

Fig.2 Hydrogeological map of coastal belt of Odisha 


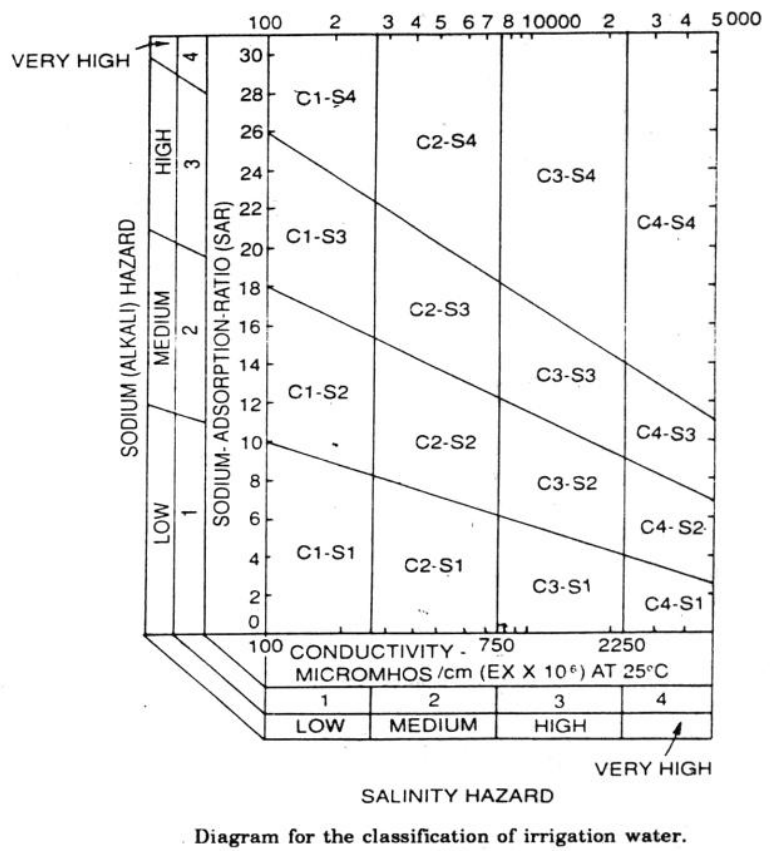

Fig.3 Diagram for the classification of irrigation water

\section{Groundwater legislation}

In the absence of groundwater legislation we should be rather cautions in our approach towards groundwater development in the coastal tract, keeping in view the Gujrat experience. Intensive investigation to delineate fresh/brakish/saline aquifers and their hydraulic parameters. Tube wells clustering to be avoided and area wise safe spacing of tube wells and well design standardized. Monitoring of quality and water levels of wells on long term basis should be done centralize data bank is to be set up.

\section{Construction of check dams/bunding}

Check dams and bunding in large number should be taken up to impound fresh water. Exploitation of buried water channels should be undertaken to kind out more fresh water sources. Creeks should be sealed with sluice to let out saline water
Development of salinity in irrigated lands of coastal regions is a major constraint to food production and hence food scarcity. In Odisha's specific situation in river mouths and river beds needs to be immediately dredged out in order that saline water carried by tidal waves into rivers and creeks flows back to sea quickly and smoothly. Tidal regulators may be constructed at appropriate points for easing the flow of saline water back into sea. People living in the coastal areas should be assisted in constructing as many water harvesting structures for storing rain and flood water which would serve the recharge of groundwater and use for domestic and irrigation purposes. The damaging effect of expanding brackish water prawn culture could be encountered only be removing the unauthorized enclosures of vast coastal tracts and by strict regulation of further land allotment to private person and agencies. The soil erosion which is a major cause of rise in riverbed may be reduced by extensive afforestation along the river banks. 


\section{References}

Behera, S.K. Salinity problem in coastal command area and its alleviation, National level training on Drainage of Irrigation Command, Ministry of Water Resources, Govt. of India \& WALMI, Orissa, 2006.

Das,P.K.,Roy,G.K.,Hydrological framework and ground water development projects in Odisha, Ministry of Water Resources, Govt. of India,2011.

Dhir, R.P. Saline waters there potentiality as a source irrigation, ICAR, New Delhi, 1977.

Gupta, S.K. Suitability of drainage techniques for prevention an control of water logging soil salinity in irrigation commands, National level training on Drainage of irrigation command, Ministry of Water Resources, Govt. of India \& WALMI, Orissa, 2006.

Report of ground water Estimation,2015, CGWB, Govt.of India.

Tyagi, N.K and Joshi, P.K. Optimal water management strategies for saline control, Journal of Irrigation and Drainage Engg., ASCE, 112, 1986.

Tyagi, N.K. and Tanwar, B.S. Planning for use of saline groundwater resources, CBIP publication no. 118, 1986.

\section{How to cite this article:}

Ashok Kumar Das, Kishore Chandra Senapati and Shishira Kanta Behera. 2020. Salinity Problem and its Management in Coastal Belt of Odisha, India. Int.J.Curr.Microbiol.App.Sci. 9(06): 1339-1345. doi: https://doi.org/10.20546/ijcmas.2020.906.166 